\title{
8
}

\section{Flow Needs for City of Detroit Customers through 2050}

Philip N. Brink, Larry J. Witt, Ashraf A. Ibrahim and Carl R. Johnson

The city of Detroit Water and Sewerage Department (DWSD) provides wastewater services for the city and 77 surrounding communities. A wastewater master plan (WWMP) has been developed for the department to provide guidance on sewer extensions and improvements that will be required to the regional collection and treatment system over the next 50 years. As part of the development of this plan, an analysis of wastewater flow needs has been completed for the city of Detroit and the surrounding communities. These flow needs have been defined in terms of wastewater flow rates that are projected to be generated within the system under both dry weather and wet weather conditions.

Wastewater flows for which projections are required are considered to consist of three components: (i) sanitary sewage flow, (ii) dry weather inflow/infiltration (DWII) or non-sewage flow, and (iii) wet weather flow (WWF). These three components are projected to future years separately, based on the factors that impact these flows.

Results have been used for evaluating potential capacity constraints of the regional system for the next 50 years. An additional goal of the analysis was to develop a uniform technical standard for assigning contract capacities for existing and new customers. This standard has helped to define what flows the regional system would be expected to accommodate versus what flows would be the responsibility of the customers to handle. Results of this analysis have been provided to the department for their use in future contract negotiations.

Brink, P., L. Witt, A.A. Ibrahim and C.R. Johnson. 2005. "Flow Needs for City of Detroit Customers through 2050." Journal of Water Management Modeling R223-08. doi: 10.14796/JWMM.R223-08

(C) CHI 2005 www.chijournal.org ISSN: 2292-6062 (Formerly in Effective Modeling of Urban Water Systems. ISBN: 0-9736716-0-2) 


\subsection{Background}

The City of Detroit provides wastewater collection, treatment and disposal services not only for the city, but also for the surrounding communities. The regional system of interceptors and the wastewater treatment plan were put into operation beginning in 1940. In the past 60 years, the system has been upgraded and expanded to serve new areas and to provide storage and treatment of combined sewer overflows.

The City provides these regional wastewater services through its Water and Sewerage Department (DWSD). The department has sewerage service agreements with 20 primary wholesale customers to provide wastewater services for the 77 suburban communities either by direct contract with the community or through a Sewer Service District. The service area of Detroit and the primary customers are shown in Figure 8.1.

The DWSD has completed or is in the process of completing a number of major construction projects for CSO control and for the upgrade and expansion of the wastewater treatment plant. To look beyond the current projects and to obtain guidance on the next 50 years of extensions and improvements to the regional collection and treatment system, DWSD retained Camp Dresser \& McKee Inc. (CDM) to prepare a wastewater master plan (DWSD, 2003) that would effectively provide cost-effective wastewater services, water quality improvements and improved quality of life.

As part of the master plan, the total flows expected to be generated within the DWSD sewer service area were projected as part of a Flow Needs analysis. These projections have been used for the master planning purposes by providing a technical basis for evaluating the sewer system capacity issues that currently exist or might arise in the future. They have also been provided to DWSD for potential use in setting flow limits in future contract negotiations. The analysis included projecting both dry and wet weather flows for DWSD customers through 2050, the planning horizon of the Wastewater Master Plan. Current contracts do not distinguish between dry weather and wet weather flow needs, but as part of the master planning, this option was investigated. Thus, flow needs were projected for flows under both dry and wet weather conditions.

Dry weather related flow needs were based on metering data available for the system. Wet weather flow needs were developed through the use of the Greater Detroit Regional Sewer Service (GDRSS) Model, a Storm Water Management Model (SWMM) developed by the city for the regional system (TenBroek, 1999). The development of the flow projections and flow needs 
has been supported by a Wastewater Master Plan (WWMP) Technical Work Group that included DWSD customers.

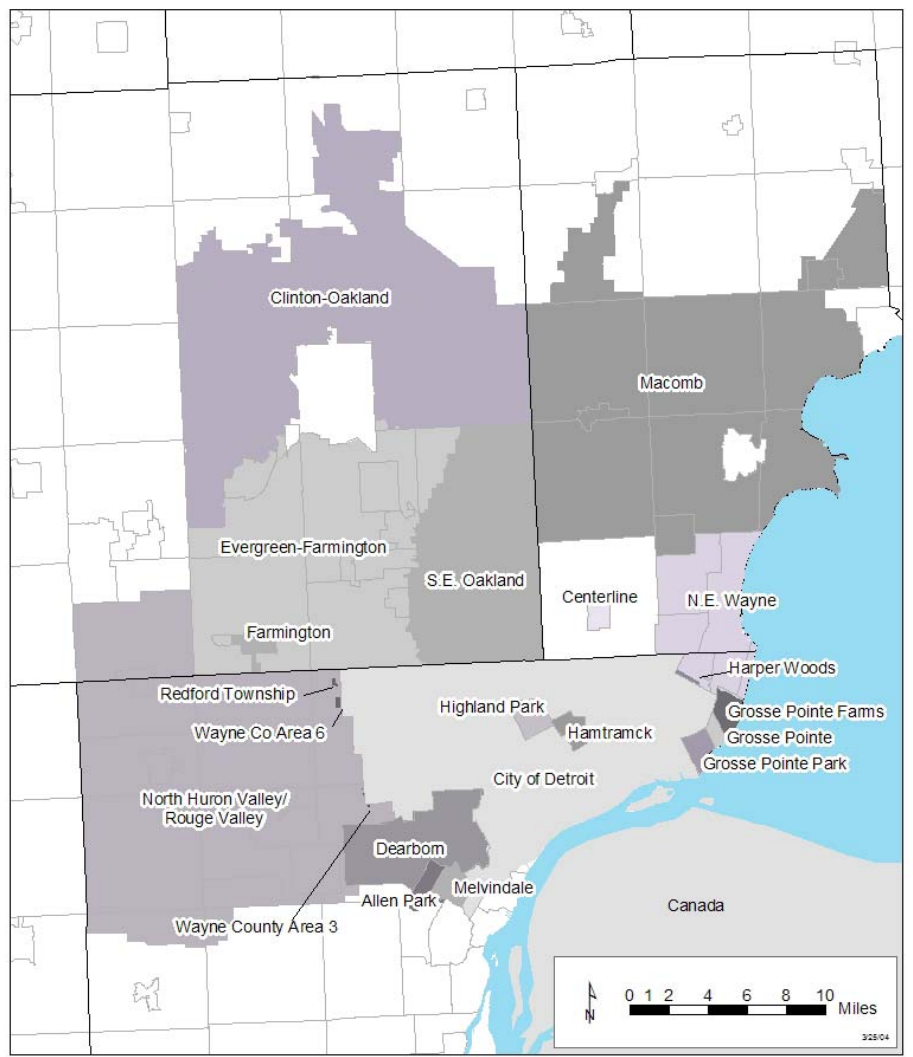

Figure 8.1 DWSD primary wholesale customers (year 2003).

\subsection{Approach}

\subsubsection{Projection of Future Flows}

Wastewater flows for which projections are required are considered to consist of three components: (i) Sanitary, (ii) Dry Weather Inflow/Infiltration (DWII), and (iii) Wet Weather Flow (WWF). These three components are projected to future years separately, based on the factors that impact these flows. Dry 
weather flow (DWF) is defined as the sum of the first two components sanitary sewage flow and DWII flow. For dry weather flows, the flow needs have been expressed in terms of three time-based parameters: (i) average daily flow, (ii) maximum month flow, and (iii) peak day flow. A peak hour flow was also developed, but only for the flows at the WWTP to check if the secondary treatment capacity would be exceeded. Wet weather flow needs were expressed in terms of peak hour flows.

The three components of flow and their projections are now described.

\section{Sanitary Flow:}

Sanitary flow includes residential flow, commercial/ business/ institutional flow and major industrial flow (called Significant Industrial Users). Residential flow has been determined to be approximately 77 gallons (290 L) per capita per day (gpcd) within the DWSD service area, based on water use from 66 communities during winter months (three-year average). It is anticipated that this rate may decrease in the future with the increased use of water saving devices; however, for purposes of estimating future residential flow, this rate is assumed to not change. Future residential flow is thus calculated using the future population times the unit rate of $77 \mathrm{gpcd}$.

Commercial, business, and institutional flow has been related to employed populations within the service area. A rate of 50 gallons (190 L) per employee per day (gped) was determined to be an average rate based on review of 12 communities, including Detroit, based on billing records. It is assumed that this rate will not change in the future. Commercial/business/institutional flow for the future is thus calculated as the future employed population times the unit rate of 50 gped.

Significant Industrial Users (SIUs) are those major industries that require a separate Industrial Waste permit with DWSD due to the volume and type of discharge. In the year 2000, there were 403 SIUs with flows of approximately $45 \mathrm{mgd}$ (170 million litres per day (mLpd)). It is projected that the SIU flows will be approximately $36 \mathrm{mgd}(136 \mathrm{mLpd})$ in 2050 as industries improve their processes to reduce water consumption and as service industries continue to supplant manufacturing in employment. For purposes of projecting to future conditions, however, it is assumed that the current SIU flows will remain a constant over the 50 y planning horizon of the WWMP. Because flows from employed populations that work at SIUs are included in the SIU flows, calculation of employed population flow requires subtracting out the SIU employed population to avoid double counting flows. 
Sanitary flow for any decade is thus calculated as the sum of these three components as follows:

$Q_{S}=$ Residents $* 77 g p c d+($ Employees $-S I U$ Employees $) * 50 g p c d+Q_{S I U}$

where the residential and employed populations are set for the year for which a projection is desired.

Dry Weather Inflow and Infiltration (DWII):

$\mathrm{Q}_{\text {DWII }}$ is non-sewage flow that enters the sewer system during dry weather. It is calculated through a flow balance by subtracting the calculated sanitary flow (Equation 8.1) from measured total dry weather flow, as follows:

where:

$$
Q_{D W I I}=Q_{M-D R Y}-Q_{S}
$$

$$
\begin{aligned}
Q_{M-D R Y}= & \text { meter (measured) flow from the flow monitoring } \\
& \text { program for dry weather flow days (discussed later), } \\
& \text { and } \\
Q_{S}= & \text { sanitary flow calculated as described in Equation 8.1 }
\end{aligned}
$$

DWII flow is a function of a number of variables, including types of sewer material and construction, sewer density (spacing, or miles of sewers per acre), soil types, construction methods, and ground water levels. While the sanitary flow component is considered to be related primarily to population and SIUs, the DWII flow component is considered to be more of a function of the type of sewer service (combined or separated) and the density of the sewers in the service area. For purposes of the Master Plan, this component was assumed to be a function of area in lieu of readily available data on sewer density and other related parameters.

DWII flows can vary during the year and from year to year due to varying influencing factors; however, in projecting to the future, the DWII long-term averages are assumed to not change within the existing sewered areas. That is, any increase in these flows that might be expected due to the aging of the sewer systems is anticipated to be offset by maintenance of the systems. For areas to be sewered in the future, a unit DWII rate based on an average DWII rate of selected areas more recently developed was used to project these flows. The use of a unit rate ( $\mathrm{gpd} / \mathrm{acre}$ ) approach was applied to the projection of the average daily flow, maximum month flow, and peak day flow by determining the unit rate for these three time bases. The different time bases 
allowed for evaluation of system capacity for different conditions. In addition, they were developed for potential use by the contract work group.

\section{Wet Weather Flows (WWF):}

Wet weather flows are flows that occur within the system in response to wet weather. Combined systems accept storm flows by design. Separated systems often exhibit a response to wet weather, commonly referred to as a raindependent inflow and infiltration (RDII), due to variety of reasons, including footing drains and illegal connections. Storm flows in combined systems and RDII flows in separate systems were determined through the use of the GDRSS Model, configured to represent both current and future (year 2050) conditions. The WWF response was considered to not change for existing sewered areas over the next 50 years. For future areas to be sewered, the values for the wet weather response parameters in the model are assumed to apply to any increase in tributary area.

For this analysis, sanitary flow is assumed to be constant on an average day basis over the year. The changes in flow rates observed within the system during the year and from year to year (short-term, ignoring small population changes) are assumed to be due to changes in DWII and WWF.

\subsubsection{Flow Data}

The flow data used for this analysis were obtained from a separate Flow Monitoring project that has been ongoing by DWSD for several years. Flow data from over 50 billing and other permanent meters used for flow balancing purposes have been collected under a rigorous quality control program for the last several years. The data are collected on 5-min time intervals. For the analysis, these were reduced to daily averages.

Annual average, maximum month, and peak day flows were determined for dry weather days. Dry days were selected based on criteria developed by the GDRSS Flow Metering project. These criteria included review of rainfall over the previous 5 days, snowmelt, and basin dewatering to ensure exclusion of flows that would include any wet weather related flows (Santini, 2001).

The meter districts in some cases represent an incremental tributary area. Flow for the incremental area is determined by subtracting the upstream meter(s) from the downstream meter. This calculation results in the flow for just the meter area, referred to as the incremental flow. The flow data are associated with meter districts, but the flow projections were made by primary customer districts. The three components of flows (sanitary, DWII, and 
WWF) for each meter district are allocated to customer districts as follows. The sanitary component is calculated directly, as the populations (residential and employed) and SIU flows are available in the database by customer district. The DWII and the WWF are distributed in proportion by area (if customer $\mathrm{A}$ is $30 \%$ of the meter district by area, then customer A would be assigned $30 \%$ of DWII and WWF).

\subsubsection{Population and Tributary Area Projections}

Populations and sewered areas were projected by decade through the year 2050. These projections were developed using input from a number of sources, including the Southeast Michigan Council of Governments (SEMCOG), a regional planning agency. In addition, communities within the planning area of the master plan were surveyed directly to determine areas they expected to be serviced by DWSD in the future. The suitability of soil for on-site sewage systems was also incorporated in projecting future sewer growth. The population growth and service area expansion projected through 2050 are provided in Table 8.1.

Table 8.1 Service area expansion and population growth.

\begin{tabular}{llll}
\hline \multicolumn{1}{c}{ Item } & Year 2000 & Year 2050 & Change \\
\hline Tributary Area (sq. miles) [sq. km] & $789[2,044]$ & $878[2,274]$ & $89[231]$ \\
Residential Population (million) & 3.02 & 3.24 & 0.22 \\
Employed Population (million) & 1.72 & 1.93 & 0.21 \\
SIU Employed Population (million) & 0.19 & 0.19 & 0 \\
\hline
\end{tabular}

The total tributary sewered area (as opposed to service area) is projected to increase by 56,900 acres ( 89 sq. miles or 231 sq. km). The projected population growth is moderate, increasing by 200,000 .

\subsection{Dry Weather Flow Needs}

Dry weather flow needs were determined based on projecting both components of dry weather flows: sanitary flows and DWII flows. The sanitary flows were calculated using Equation 8.1 to get the results provided in Table 8.2. Based on the increase of residential and employed populations, the sanitary component of dry weather flow is projected to increase from 354 mgd to $381 \mathrm{mgd}$ (1340 to $1440 \mathrm{mLd})$, an increase of $27 \mathrm{mgd}(102 \mathrm{mLd})$. 
Dry weather flow needs were determined for average day, maximum month and peak day. Using measured flow data available for all or part of four years, an analysis of existing dry weather flows was performed for both an average over the four years of data available (1998 through 2001) and for the year 2001. The year 2001 had the highest average and peak dry weather flows of the four years and therefore considered worst case for Master Plan purposes.

Table 8.2 Existing and projected populations and sanitary flows $\left(Q_{S}\right)$.

\begin{tabular}{|c|c|c|c|c|c|c|c|}
\hline & \multicolumn{7}{|c|}{ Existing Dry Weather Flow Calculations } \\
\hline & \multicolumn{3}{|c|}{ Population (millions) } & \multicolumn{2}{|c|}{$\mathrm{Q}_{\text {sIU }}$ Flow } & \multicolumn{2}{|c|}{ Sanitary Flow* } \\
\hline & Residents & Employed & SIU Emp. & (mgd) & $\left(\mathrm{m}^{3} / \mathrm{d}\right)$ & (mgd) & $\left(\mathrm{m}^{3} / \mathrm{d}\right)$ \\
\hline 2000 & 3.02 & 1.72 & 0.19 & 45 & 170,000 & 354 & $1,340,000$ \\
\hline 2050 & 3.24 & 1.93 & 0.19 & 45 & 170,000 & 381 & $1,442,000$ \\
\hline
\end{tabular}

The month of February 2001 was determined to represent the peak month flow as this month had the highest dry weather flow of all the months in the year. The peak day dry weather flow for existing conditions was based on February 24, 2001. This day had the highest total flow at the WWTP of all the days classified as DWF days in the year 2001.

For each separate sewer service area, the sanitary flow was calculated and subtracted from the total dry weather flow (obtained from the flow-metering program) to determine the DWII flow. The DWII, as discussed, was unitized by area as gallons per day per acre (gpd/acre). Based on this analysis, the unit rate was found to vary from below 50 to over $300 \mathrm{gpd} /$ acre (470 to over 2780 $\mathrm{Lpd} / \mathrm{ha}$ ). In general, the higher rates are associated with older communities. It is expected that rates from new sewered areas will correspond to the lower unit rates. Using an average of seven meter districts of more recent construction, a unit rate of 53, 70, and $67 \mathrm{gpd} / \mathrm{acre}$ (492, 652, and $622 \mathrm{Lpd} / \mathrm{ha}$ ) was calculated for average daily, maximum month, and peak day time periods. The result of the peak day unit rate being slightly less than the maximum month unit rate is because the peak day was selected based on flows at the WWTP. This day was not always the peak flow day for individual meter districts, as evidenced in the resulting unit rates. These unit rates were used for all areas projected to be sewered in the future through the year 2050 . 
The existing and projected DWII flows are provided in Table 8.3 for the average daily for both the year 2001 data and the four years of data collected, as well as for maximum month and peak day. These were calculated for each primary customer, however, only the totals are generally provided due to space limitations.

As the results indicate in the table, the amount of additional DWII flows projected from new areas expected to be sewered by 2050 is relatively small, being just over $1 \%$ of existing DWII in each case.

Future dry weather flows are calculated simply by adding the future sanitary and future DWII flows. These were calculated for each primary wholesale customer. The totals for the regional system are provided in Table 8.4 for the time-based periods analyzed.

Table 8.3 Existing and projected DWII flows ( $\left.Q_{D W I I}\right)$.

\begin{tabular}{|c|c|c|c|c|c|c|c|c|}
\hline \multirow[b]{2}{*}{ Time Base } & \multicolumn{2}{|c|}{ Existing DWII } & \multicolumn{2}{|c|}{ DWII Unit Rate } & \multicolumn{2}{|c|}{$\begin{array}{c}\text { Additional } \\
\text { DWII* }\end{array}$} & \multicolumn{2}{|c|}{ Year 2050 DWII } \\
\hline & $\operatorname{mgd}$ & $\mathrm{m}^{3} / \mathrm{d}$ & $\begin{array}{c}\mathrm{gpd} / \mathrm{a} \\
\mathrm{c}\end{array}$ & $\begin{array}{c}\mathrm{m}^{3} / \mathrm{d} / \mathrm{k} \\
\mathrm{m}^{2}\end{array}$ & $\operatorname{mgd}$ & $\mathrm{m}^{3} / \mathrm{d}$ & mgd & $\mathrm{m}^{3} / \mathrm{d}$ \\
\hline $\begin{array}{l}\text { Av. Daily } \\
2001\end{array}$ & 251 & 950,100 & 53 & 50 & 3.0 & 11,400 & 254 & 961,500 \\
\hline $\begin{array}{l}\text { Av. Daily } \\
\text { 1998-2001 }\end{array}$ & 195 & 738,200 & 53 & 50 & 3.0 & 11,400 & 198 & 749,600 \\
\hline $\begin{array}{l}\text { MaxMonth } \\
\text { (Feb.2001) }\end{array}$ & 329 & $1,245,400$ & 70 & 65 & 4.0 & 5,100 & 333 & $1,260,500$ \\
\hline $\begin{array}{l}\text { Peak Day } \\
2001.0224\end{array}$ & 403 & $1,525,500$ & 67 & 63 & 3.8 & 4,400 & 407 & $1,539,900$ \\
\hline
\end{tabular}

Table 8.4 Existing and projected DWFs.

\begin{tabular}{lcccc}
\hline & \multicolumn{2}{c}{ Year 2000 } & \multicolumn{2}{c}{ Year 2050 } \\
\hline Time Base & $(\mathrm{mgd})$ & $\left(\mathrm{m}^{3} / \mathrm{d}\right)$ & $(\mathrm{mgd})$ & $\left(\mathrm{m}^{3} / \mathrm{d}\right)$ \\
\hline Av. Daily 2001 & 605 & $2,290,100$ & 635 & $2,403,800$ \\
Av. Daily 1998-2001 & 549 & $2,078,200$ & 579 & $2,191,700$ \\
Maximum Month (Feb. & 683 & $2,585,400$ & 714 & $2,702,700$ \\
2001) & & & & \\
Peak Day (Feb. 24, & 757 & $2,865,500$ & 788 & $2,982,200$ \\
2001) & & & & \\
\hline
\end{tabular}


The existing Detroit WWTP and the regional system has capacity to handle all of the DWF from the projected growth in the existing service area and in the planned expansion area over the next 50 years. The results were provided to DWSD for potential use in future contract negotiations.

The peak hour flows under dry weather conditions were not developed for each customer, as the critical need on a peak hour basis for the customers is the peak flow during wet weather conditions. As part of a separate analysis, however, the peak hour dry weather flow at the WWTP was projected to 2050. The results confirmed that the plant's secondary capacity of $930 \mathrm{mgd}$ $\left(3,520,000 \mathrm{~m}^{3} / \mathrm{d}\right)$ would not be exceeded under dry weather conditions. As part of the separate analysis, the uncertainty in these projections, including accounting for several communities that currently indicate that they are not planning on joining the regional system, was reviewed. Due to uncertainties inherent in any projection of future flows, DWSD plans to review these predictions every 10 -y to confirm that the plant's capacity will continue to be sufficient as currently projected.

\subsection{Wet Weather Flow Needs}

In determining wet weather flow needs, the history of how the regional sewer collection system developed and an understanding of the existing infrastructure needs to be taken into consideration. Detroit regional system consists of combined sewer service systems in the older, core urban areas surrounded by separated systems in the newer suburban areas. Since the 1930s, DWSD has used design standards of $0.4 \mathrm{cfs}$ and $0.5 \mathrm{cfs}(11.3 \mathrm{~L} / \mathrm{s}$ and $14.1 \mathrm{~L} / \mathrm{s})$ per 1,000 persons for separate and combined systems, respectively, to define a peak flow rate to be intercepted for wastewater treatment (National Sanitation Foundation, 1964). This rate is an empirical relationship that provides for dry weather flows and some amount of wet weather flows. This standard is generally consistent with the Ten-States Standards (Great Lakes, 1997) and the ASCE/WEF Manual of Practice (ASCE, 1969) for designing interceptors, and was intended to be applied for tributary areas with populations greater than 20,000 .

Since the 1980s, with the advent of computer models and more sophisticated flow monitoring techniques, specific design storms, such as a $10 \mathrm{y}$ frequency, $1 \mathrm{~h}$ duration storms can be simulated. As part of a separate review to determine what capacity the regional system could accommodate for SSO issues, a number of various design events were simulated. This 
analysis is described further in the chapter titled SSO Control Alternatives in Detroit's Regional Collection System, in Monograph 12 in this series (Taylor, 2004). Results of this analysis suggested that the system could accommodate allowable flows (discussed next) from a 10-y, 1-h design event as defined for growth (summer) conditions (the analysis distinguishes between summer and winter conditions with respect to both the types of storm events and the response of the sewershed).

A standard to define allowable flow limits was developed based on review of current $10-\mathrm{y}, 1-\mathrm{h}$ peak flows resulting from each community within the DWSD service area for which model results were available. The peak rates, after removing employed and SIU flows, were unitized using residential population solely for purposes of being able to compare the peak rates on a common basis in terms of $\mathrm{cfs} / 1000$ population. These peak rates were then plotted against the percent of homes with connected footing drains within each community to create the chart shown in Figure 8.2.

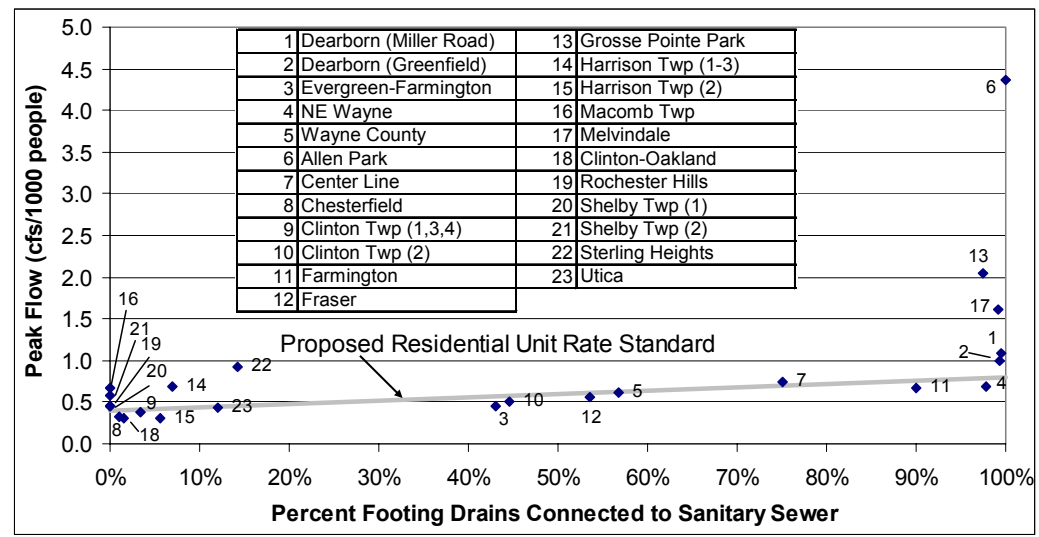

Figure 8.2 Modeled peak rates and proposed residential unit rate standard.

The $\%$ footing drains connected accounts for the degree of wetness in the system, which typically can be related to the age of the system and/or the type of construction methods. In this case, the presence of footing drains connected to the sanitary sewer system was used to define the degree of wetness. This approach is not intended to imply that wet weather flows from footing drains can be determined as a function of population. Rather, the result is to define a higher unit rate for separate sewer service areas with footing drains. Historically, no distinction was made for whether footing drains were 
connected to the sewer system in separate sewer service areas. This proposed standard recognizes a need for a higher rate for areas where footing drains are connected.

A linear regression was performed on the data with outliers removed. A tolerance of $0.1 \mathrm{cfs}$ or $2.8 \mathrm{~L} / \mathrm{s}(\sim 25 \%)$ was added to get a line that ranged from $0.4 \mathrm{cfs}(11.3 \mathrm{~L} / \mathrm{s}) / 1000$ residents for sanitary systems with no footing drains connected to the sanitary system to $0.8 \mathrm{cfs}(22.6 \mathrm{~L} / \mathrm{s}) / 1000$ residents for $100 \%$ of footing drains connected. The resulting residential unit rate standard line, shown in Figure 8.2, is defined by the following equation:

$$
\text { Residential Unit Rate Standard }\left(c f_{S} / 1000\right)=F D \% * 0.4+0.4
$$

This rate allows for all expected sanitary flow and some amount of wet weather flow consistent with past practices for areas without footing drains (NSF, 1964). For areas with footing drains, the rate allows for some additional wet weather response that was determined could be accommodated by the regional system.

In addition to defining an allowable unit rate for separated areas, a unit rate of $0.5 \mathrm{cfs}(14 \mathrm{~L} / \mathrm{s}) / 1000$ residents was set as an allowable unit rate for combined areas, which is consistent with the historical design criteria used for combined areas to sized interceptors (NSF, 1964). There are exceptions for some combined areas, which will be discussed shortly. For customers with both combined and separate sewer service areas, an average unit rate weighted by sewer type area is calculated to determine the applicable unit rate.

The proposed flow limit is then calculated as follows:

$$
Q_{r}=\text { Unit Rate } * \text { Residents/1000 }
$$

The subscript $r$ denotes that the flow limit as calculated reflects the residential flow needs only. The overall allowable peak limit $\left(Q_{a p}\right)$, called the calculated wet weather treatment peak, is calculated as the residential flow limit plus an allowance for employed flows and SIU flows:

$$
Q_{a p}=Q_{r}+Q_{e}+Q_{S I U}
$$

This peak defines what is considered to be a reasonable or allowable peak discharge rate from a community to the DWSD system resulting from a $10 \mathrm{y}$, $1 \mathrm{~h}$ design event. An example calculation is provided for the EvergreenFarmington District, a sewer district that in turn serves a number of 
communities that are in that district. This district has 4,220 acres $(1,715$ ha) of combined; 22,871 acres (9,297 ha) of separate with footing drains; and 41,553 acres $(16,891 \mathrm{ha})$ of separate without footing drains. The comparable unit rate calculates to be $0.54 \mathrm{cfs}(15.28 \mathrm{~L} / \mathrm{s}) / 1000$ residents $[(22,871 /(22,871+$ $41,553)(0.4)+0.4) *(22,871+41,553)+0.5 * 4,220) /(4,220+22,871+$ $41,553)]$. With a residential population of 271,572 , the residential need calculates to be $147 \mathrm{cfs}\left(359,700 \mathrm{~m}^{3} / \mathrm{d}\right)$. Adding in the employed flows and the SIU flows results in a total calculated wet weather treatment peak of 172 cfs $\left(420,100 \mathrm{~m}^{3} / \mathrm{d}\right)$ for this district.

Table 8.5 Results of allowable wet weather treatment peak analysis.*

\begin{tabular}{lccccc}
\hline $\begin{array}{l}\text { Primary Wholesale } \\
\text { Customers \& Detroit }\end{array}$ & $\begin{array}{c}\text { Service } \\
\text { Type }\end{array}$ & $\begin{array}{c}\text { Comparable } \\
\text { Unit Rate }\end{array}$ & \multicolumn{3}{c}{ Calculated Allowable Wet Weather } \\
Treatment Peak
\end{tabular}

*These calculated peaks were used by the WWMP for review of regional system capacity purposes. 
The calculated wet weather treatment peaks were calculated for each decade from 2000 through 2050 for each customer in this manner. Results are provided for the year 2050 in Table 8.5 for the primary customers. This table includes the sewer service type and the comparable unit rate calculated for each customer. The total projected peaks for the year 2050 is $1,151 \mathrm{mgd}$ $\left(4,357,200 \mathrm{~m}^{3} / \mathrm{d}\right)$ for 2050 . The system has capacity for this peak for transport to the WWTP for treatment.

Some combined sewer service communities have what can be understood to be transport needs in addition to treatment needs. In these cases, the existing contract peak rates do not represent expected treatment rates, but rather the transport of storm flows through the DWSD collection and/or interceptor sewer system to a downstream facility with potential for overflow to a receiving water during wet weather conditions. The city of Hamtramck, for instance, does not have access to a receiving stream whereby its combined system could be relieved during wet weather. Its contract peak of $1244.5 \mathrm{cfs}$ $\left(35.2 \mathrm{~m}^{3} / \mathrm{s}\right)$ allows for storm flows to be directed towards the Detroit River Interceptor (DRI) via the DWSD sewer collection system. A portion of this flow would be intercepted at the DRI, along with Detroit's flows, for treatment. Storm flows in excess of the interceptor capacity would be discharged to the Detroit River. Another example of a transport capacity that applies to several customers involves the transport of combined flows to a point downstream of Detroit's water intake for drinking water on the Detroit River.

In developing recommended peak capacity limits for existing customers with existing facilities and associated transport needs, the calculated wet weather treatment peaks were compared to existing contract limits. For evaluation of capacity issues that currently exist or that might arise in the future, the larger of the two limits was used for each customer.

The regional system was evaluated using the larger limit of either the standard or the existing contract limit and was found to have adequate transport capacity through the year 2050, once current or planned projects are completed.

An additional alternative was developed to investigate the potential for the regional system to accept additional SSO flows from several of the customers without causing potential for additional basement flooding or other adverse impacts to the regional system. The system was found to have additional capacity for these customers, but this extra capacity is understood to be available on a short-term basis as to be negotiated to provide time for these communities to implement various control strategies and reduce peak discharges to limits allowed by new service contracts. 


\subsection{Summary}

The flow needs for the primary wholesale customers of DWSD have been determined for average day, maximum month, and peak day for dry weather flow conditions and peak hour for wet weather conditions through the year 2050. Dry weather flow needs were developed based on meter data and projected to future conditions based on populations and sewer area growth for all 20 primary customers. It was determined that the regional system and the WWTP will have capacity for dry weather flows as projected in the year 2050. The peak hour flow under dry weather conditions was not determined for each customer, but it was evaluated for flows at the plant to check for the adequacy of the plant's secondary capacity. Results confirm that the plant will have the required capacity and then some for these projected flows. Due to the inherent uncertainties in projecting future flows, DWSD intends to review these projections every 10 -y to confirm these results.

Wet weather flow needs were calculated based on a standard that accounted for various types of sewer service systems. This standard defined a capacity limit for each customer that the regional system would be able to accept for transport and treatment. Flows above this limit would be the responsibility of the customers to address. Recognition of existing contracts and existing facilities within the system was made by defining a transport flow need in addition to a treatment need. The regional system was evaluated using the larger limit of either the standard or the existing contract limit and was found to have treatment and/or transport capacity through the year 2050, once current or planned projects are completed. In addition, an alternative reviewed the potential to provide additional capacity on a short-term basis for several of the communities working to solve SSO issues. This information has been provided to DWSD for their use in future contract negotiations.

\section{References}

American Society of Civil Engineers (ASCE) and Water Pollution Control Federation (WPCF). 1969. "Design and Construction of Sanitary and Storm Sewers." Manual and Reports on Engineering Practice No. 37 (ASCE) and Manual of Practice No. 9 (WPCF), joint committee of ASCE and WPCF.

Detroit Water and Sewerage Department (DWSD). 2003. "Wastewater Master Plan" Detroit, MI 48226 
Great Lakes-Upper Mississippi River Board of State and Provincial Public Health and Environmental Managers. 1997. "Recommended Ten States Standards for Wastewater Facilities." Health Education Services, Albany, NY 12224.

National Sanitation Foundation. 1964. "Report on Metropolitan Environmental Study Sewerage and Drainage Problems - Administrative Affairs." Report.

Sherman, B.J., P. Brink and M.J. TenBroek. 1998. "Spatial and Seasonal Characterization of Infiltration/Inflow for a Regional Sewer System Model." Journal of Water Management Modeling R200-13. doi: 10.14796/JWMM.R200-13.

Santini, A., P. Brink, B.J. Sherman and M.J. TenBroek. 2001. "An Equivalent Rainfall Technique to Identify Dry Weather Flow Data for City of Detroit Flow Balance Analysis." Journal of Water Management Modeling R207-17. doi: 10.14796/JWMM.R207-17.

Taylor, M., P. Brink and M.C. Stonehouse. 2004. "Analysis of SSO Control Alternatives within the City of Detroit's Regional Collection System." Journal of Water Management Modeling R220-08. doi: 10.14796/JWMM.R220-08.

TenBroek, M.J., G. Fujita, P. Brink, B.J. Sherman and D. White. 1999. "Detroit Water and Sewerage Department Model Extensions and Project Overview." Journal of Water Management Modeling R204-11. doi: 10.14796/JWMM.R204-11.

Walch, Marc, Thomas Christ, Kathleen Leo, Stephanie Ross, and William Brant. 1995. "Computer Modeling of Sanitary Sewer Overflows Resulting from Peak Flow Conditions." National Conference on Sanitary Sewer Overflows: U.S. EPA, Washington, DC. 